FATIGUE IN LUBRTCANIS ENVIRONMENI

P. POUDOU* ${ }^{*}$ G. NOUAIL ${ }^{*}$, J. AYEL ${ }^{*}$ and G. PLUVINAGE ${ }^{* *}$

The lubricant as environment modifies the fatigue behaviour, patigue contact. The lubricant influence is studied :

- on fatigue crack propagation which shows a strong influ-

ence of lubricant and temperature effect.

crack initiation on which lubricant has a beneficial

effect.

Fractography and surface analysis with IAMMA micro-probe analysis indicate that water contained in oil has an effect

analysis indicate that water contain crack propagation.

\title{
INTRODUCTION
}

Rolling contact fatique appears on the surface of components such as cams and Rolling forst step is the formation of little toppets, gears with pits and flakes which can develop and finally contact tests conducted on Generally, this phenomenon is studied by rolling bearings and thrust bearing rigs,

four-ball fatigue machine, full scale ball bearlng and toppets rigs, etc ...

in the interaction

The interpretation of these results is difficult to rank lubricants and

of several parameters, but these

The lubricant has two major influences :

- Influence on rheological and tribological properties.

- Influence on fatigue mechanism.

lubricant controls the operating conditions of lubricated contac

thickness, friction coefficient, boundary film adherence and (on have a strong influence surface wear. These lubricant parameters are known to hamperature contact. Luon fatigue pitting by disturbing stress condition and known. Same authors : bricant influence on fatigue mechanism are not well al (3) have studied the Galvin and Maylor (1), Kennel (2) and Amnstrong specimen in rotating Galvin and May lubricant on the total life of steel specimen in rotang the influence of the lubricant on the to (4) are the unique authors studying the beam fatigue. Polk, Murphy and Rowe phase with notched rotating specimens. lubricant effect on the propagating phase with notched rota

* Institut Français du Pétrole, RUEII-MAIMAISON, France

* Institut Françals du Petú Mécanique, Universite

I 
Considering that friction leads to intraduce tensile stress in the contact stress distribution and the maximum value of these stresses are proportional pressure test, and considering max $\left.=2 \mu \mathrm{P}_{\text {max }}\right)$ with $\mathrm{P}_{\text {max }}=$ maximum hertzian pressure test, and considering maxt tensile stresses have the major effect on cess in opening mode.

A particular attention was payed to initiation stage and to propagation stage by using specific fatigue tests.

\section{Influence of lubricant on fatigue crack propagation} steel.

Crack propagation tests were led in lubricant enviromment on $35 \mathrm{NCD} 16$

\begin{tabular}{cccccccc}
\multicolumn{6}{l}{ The chemical composition is the following (in percentage) : } \\
\hline C & Mn & Ni & Si & Cr & Mo & P-S \\
$0.3-0.37$ & $0.3-0.6$ & $3.7-4.2$ & $0.1-0.4$ & $1.6-2$ & $0.3-0.5$ & $0.035 \%$ \\
\hline
\end{tabular}

Tests were performed on CTW 80 B 20 samples (2O mm thick) put into an immersion cell filled with a lubricant which iscirculating around the specimer. the cell and the propagation in the air, then the lubricant is. introduced into the cell and the propagation starts under load frequency of $5 \mathrm{~Hz}$ and a load ratio $R=0.1$. Crack growth measurement was achieved with an optical method. growth are plotted in a bilogarithmic. diagram for the variation of the crack growth rate da/dN versus stress intensity factor range $\Delta \mathrm{K}$.

The following parameters were studied (basic oil, additives, temperature, viscosity) :

- The effect of basic oil on crack propagation rate as reference ; tests were also led in the air and the crack growth rate curve was linear according to Paris law. In presence of $200 \mathrm{NS}$ basic oil, at $80^{\circ} \mathrm{C}$, the crack growth curve deviates from linear shape (FIg. 1). The maximum deviation is in intermediate stress intensity factor range. At low and high $\Delta \mathrm{K}$ values, the two curves are quite the same. This generally indicates an environment influence. Residence time of lubricant is reduced at low and high crack growth rates.

- The effect of additives : we have also added three additives in the basic oil :

$$
\begin{aligned}
& \text { - ditertiododecyl-polysulphyde (S.A.) ( } 3 \% \text { by weight) } \\
& \text { - triaryl-phosphate (S.A.) ( } 2 \% \text { by weight) } \\
& \text { - chlorine additive (CA) ( } 3 \% \text { by weight) }
\end{aligned}
$$

Tests were conducted at $80^{\circ} \mathrm{C}$. The results are reported in terms of relative speed versus logarithm of the stress intensity factor. The relative speed is defined as the ratio of the speed measured in a given environment to the speed measured in the air. The results show that the behaviour of lubricant containing these three additives are quite similar ; they present a maximum effect in intermediate stress intensity factor range. Ditertiododecyl-polysulfide has a lower influence.

- The effect of temperature on crack growth rate in lubricant environment. The $40^{\circ} \mathrm{C}-100^{\circ} \mathrm{C}$ range was investigated with the basic oil. Results are presented in the same manner : relative crack growth rate versus logarithm of 
of stress intensity factor range.

- The effect of viscosity. Tests were conducted with straight mineral oils of different viscosities at $80^{\circ} \mathrm{C}$ (100 NS, $200 \mathrm{NS}, 350 \mathrm{NS}, 600 \mathrm{NY}$ ). Their viscosities are given in the following table:

\begin{tabular}{ccccc}
\hline OIL & $100 \mathrm{NS}$ & $200 \mathrm{NS}$ & $350 \mathrm{NS}$ & $600 \mathrm{NS}$ \\
$\begin{array}{l}\text { VISCOSITY } \\
\text { at } 80^{\circ} \mathrm{C} \text { (cst) }\end{array}$ & 6.0 & 9.8 & 15.6 & 21.7 \\
\hline
\end{tabular}

It seems that viscosity is not a governing parameter (Fig. 4).

\section{Crack initiation}

Tests for studying crack initiation are conducted on the same CT specimens. Mechanical slots have different acuteness and are more blunted than for crack propagation tests $(\rho=2.5 \mathrm{~mm}$ and $\rho=1 \mathrm{~mm})$. The same immersion cell is used. The loading frequency is $10 \mathrm{~Hz}$. The behaviour of the materials towards crack. crack. We use for this determination a crack opening displacement gauge which is fixed in the front of the notch. Before any crack develop in the specimen, the signal delivered by the gauge is constant. When fatigue cracks start to tiation cycles by the signal signal increases. We determine the number of initiation cycles by the signal changement. A series of tests conducted in ambient air are used as reference. Test have been led in 200 NS and 200 NS oils
plus $3 \%$ of a chlorinated wax.

The results (Fig. 5) are reported in terms of the number of cycles for fatigue crack initiation $\mathrm{Ni}$, versus the $\Delta K / \sqrt{\rho}$ parameter used by many workers (5). We find a beneficial effect of lubricant environment slightly higher than the scattering band which we can expect in this kind of tests.

\section{DISCUSSION}

The influence of lubricant on crack propagation gives an acceleration of crack propagation with temperature. The maximm effect is for $60^{\circ} \mathrm{C}$. An observation of the fracture surface shows a corrosion effect at $40,60^{\circ} \mathrm{C}$. On the contrary, at $80^{\circ}-100^{\circ} \mathrm{C}$, the fracture aspect is similar to that one obtained after tesfor the tests conducted at $40^{\circ} \mathrm{C}$ fractographs show intergranular failure areas the same pattern as that one obtained with $60^{\circ} \mathrm{C}$, whereas at $80^{\circ}$ and $100^{\circ} \mathrm{C}$ we found (ductile pattern as that one obtained with the tests conducted in the air (ductile tearing fracture mode - Fig. 6).

Surface analysis with LAMMA microprobe analysis (Laser Microprobe Mass Analysis) indicates the presence of iron oxide. We assume that the acceleration of crack propagation is due to a fatigue corrosion mechanism induced by
water in oil.

For verification, we make a fatigue crack propagation test in deshydrated oil with molecular screen (20 p.p.m. of water). Crack propagation decreases in comparison with the oil containing 80 p.p.m. of water but it seems that very few quantities of water in oil are enough to induce stress corrosion fatigue.

The effect of temperature can be explained by a decreasing os viscosity of $200 \mathrm{NS}$ oil (39 cst at $40^{\circ} \mathrm{C} ; 6.1 \mathrm{cst}$ at $100^{\circ} \mathrm{C}$ ) and the decreasing of water contents with temperature. 
The relative beneficial effect of lubricant on crack initiation can be explained by exclusion of humidity pitting and environment protection. This result is an experimental controversy to literature assumption generally presented. Lubricant influence has not been found on crack initiation but on crack propagation. All tests are conducted in mode I loading, assuming that lubricant influence, as environment agent, is the same in any kind of loading. Stress has also a strong influence on mechanical loading in contact fatigue. important tribution is influenced by friction coefficient, tensile stress, and important shearing stress are present in pressure contact. Stress intensity and distribution are modified by the friction coefficient and crack propagated in mixed mode condition (I + II).

In this condition, verification of the lubricant influences on crack propagation through rupture criteria is required. The modification of crack propagation allowed spalling phenomena on surface.

\section{CONCLUSIONS}

To explains lubricant influence as environment on fatigue, conventional tests are led.

We notice a small beneficial effect on crack initiation.

Fatigue crack propagation is very sensitive to lubricant.

The increasing of crack speed is depending upon the temperature and stress intensity factor range.

It seems that water contents have a stress corrosive effect during each propagation under lubricant environment.

\section{REFERENCES}

1. Galvin, G., Naylor, H., 1964-1965, "Effect of lubricants on the fatigue of steel and other metals", Proc. Inst. Mech. Eng., vol. 179, Pt 1, nº 27, 857-875.

2. Kennel, M., 1966, "Influence de divers lubrifiants sur la résistance à la fatigue des métaux", Thesis, University of Paris.

3. Armstrong, E.L., Leonardi, S.L., Murphy, W.R. and Wooding,. P.S., 1968, "Evaluation of water accelerated bearing fatigue in oil lubricated ballbearings", Lubrication Engineering, vol. 34, 1, 15-21.

4. Polk, C.J., Murphy, W.R., and Rowe, C.N., 1975, "Determining fatique crack propagation rates in lubricating environments through the applica tion of fracture mechanics technique", ASLET Trans., vol. 18.4, 290-298.

5. Baus, A., Lieurade, H.P., Sanz, G., Truchon, M., 1977, "Etude de l'amorçage des fissures de fatigue sur des éprouvettes en acier à très hautes résistances possédant des défauts de formes et de dimensions différentes" Revue de Métallurgie . 


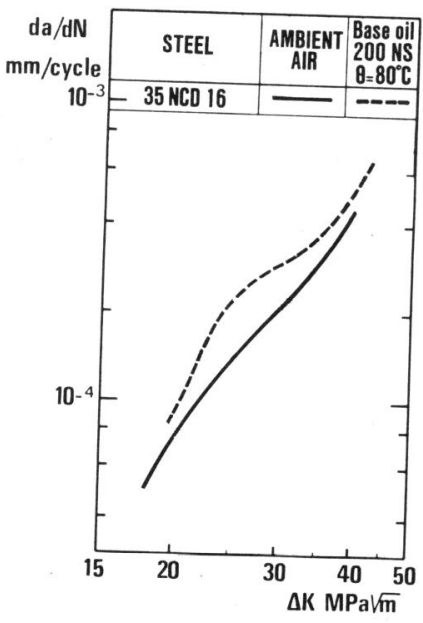

Figure 1 Effect of the lubricant on the crack propagation rate

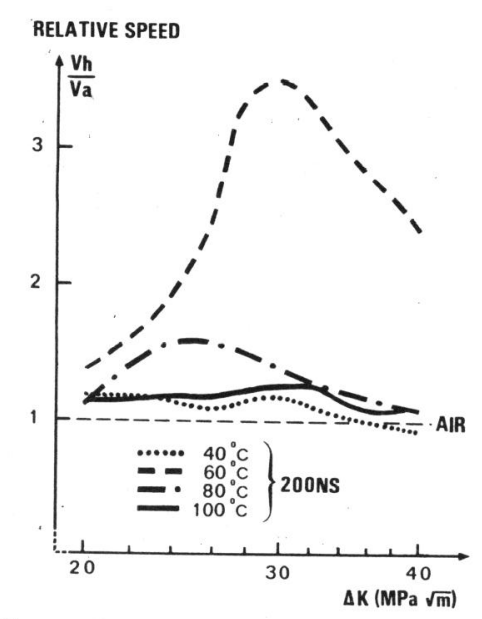

Figure 3 Effect of temperature on crack propagation rate

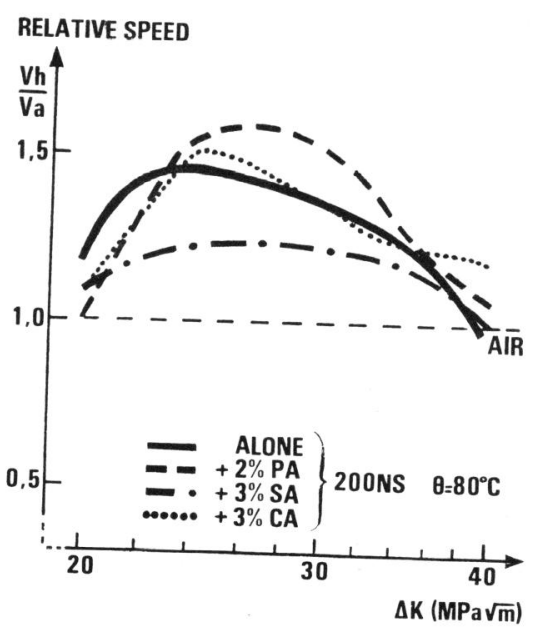

Figure 2 effect of additives on the crack propagation rate

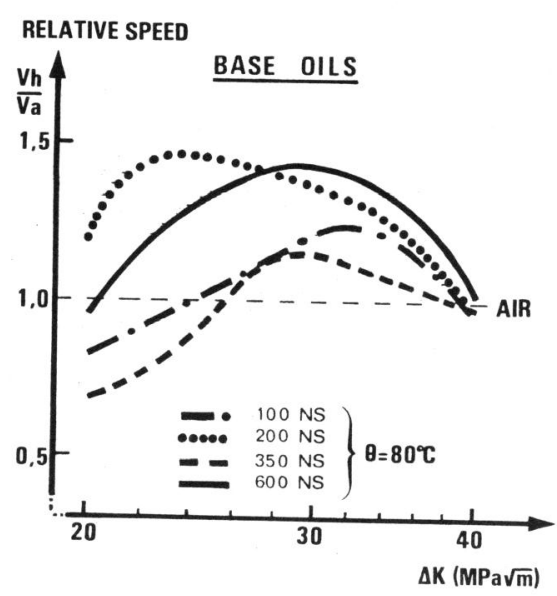

Figure 4 Effect of lubricant viscosity on crack propagation rate 


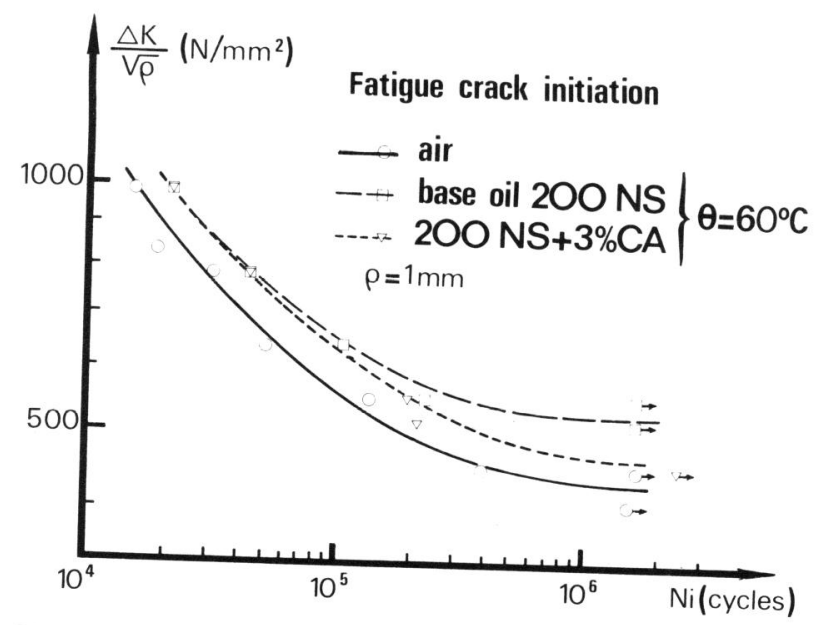

Figure 5 Effects of lubricant on the fatigue crack initiation
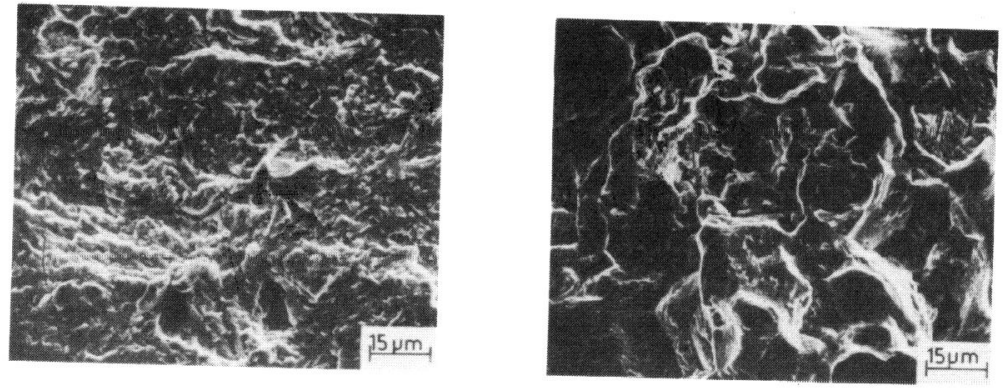

Figure 6 SEM micrographs of the fracture surfaces

a) Test run in ambiant air - b) Test run in 200 NS oil at $60^{\circ} \mathrm{C}$ 


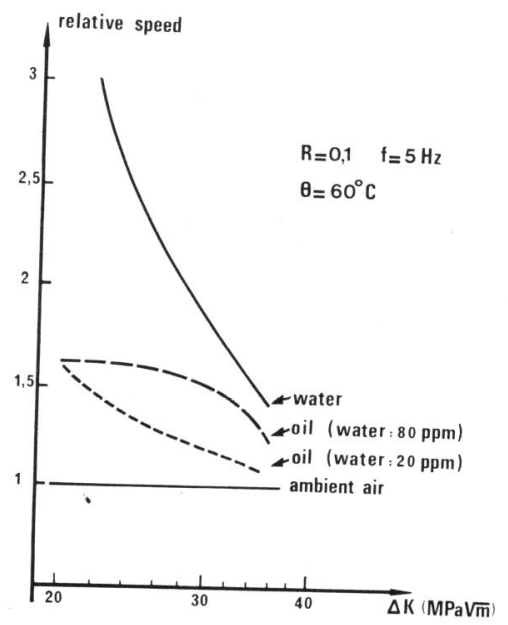

Figure 7 Camparison of fatigue crack propagation with water contents 